\title{
How are we to Live? Ethical Life and Good Life Interview Peter Singer with Freddy Santamaría 12 March 2019, Melbourne, Australia
}

\author{
Santamaría-Velasco F* \\ Professor of philosophy, Pontifical Bolivarian University, Colombia
}

*Corresponding author: Freddy Santamaría Velasco, Pontifical University of Salamanca (UPSA), Senior Researcher Pontifical Bolivarian University, Professor of philosophy of language, Colombia, Email: freddy.santamariave@upb.edu.co
Freddy Santamaría: How did you come to the idea of studying philosophy? In other words, what inspired you to study and then devote yourself to philosophy as your profession?

Peter Singer: Well I did not originally intend to. Have a career in philosophy but I thought it was an interesting area to learn something about and you know. When I was at high school we didn't study any philosophy at high school so it was something I didn't know very much about. But I had my sister had a boyfriend who does philosophy so I talked to him about it and it sounded interesting and I. I always liked having a good argument a good discussion so I decided to try it. And when I tried it I found that there were really interesting questions to talk about that philosophers discussed. Quite important issues. We started out with a course on Plato was the introductory course here. At that time and Plato obviously raises questions about how we ought to live. So these are important questions that I became interested in discussing.

Freddy Santamaría: How can philosophy help us today in our daily lives? Can you help us to be more ethical?

Peter Singer: I think philosophy has something to offer everybody not necessarily to make it a big area of their study all the time but at least to become acquainted with some of the discussions that people have had over many centuries about values and what's important what really matters and how one should live one's life. I think that philosophy is important ultimately because of its practical implications, which is not to deny that there is intrinsic interest in finding answers to questions that are not practical in understanding more about the universe and reality and how we know what ultimately exists. All of those are interesting questions. But in a world in which there are so many problems, there are so many things that are going wrong in terms of people living in poverty in terms of what we're doing to the climate of our planet, in terms of the way we treat non-human animals

Freddy Santamaría: You have given us many examples of how simple, common people can help the world in general and specific people as well. For instance, there is a movement, led by young people in the United States (Ryan Nicodemus y Joshua Fields Millburn), actually, without any pretensions of philosophical or theoretical grounds, but that has been very effective, called minimalism, which consists of living with what is absolutely necessary, not more than what we need. 3 shirts, 2 pants, 2 pairs of shoes, etc.. Do you think that these movements and others are a response and a sign that there is a new mentality? Can we be optimistic?

Peter Singer: I would like to see a lot more people living more simply and then maybe we could say that there is this new movement and that there is a changing mentality, but most people are not living like that, in fact, I think more and more people are going in the opposite direction of seeing buying things that they don't really need as an important part of their life, it's almost like a recreational activity to go shopping and buy things that they don't need and then they dispose of them, you know, they get rid of them quite rapidly; and of course that again goes back to what we were saying about the power of advertising.

And it's very hard for a movement like minimalism to compete with the billions of dollars that are constantly being spent to encourage us to consume more. So, I would like to believe that there is a new mentality but, there are some signs of it in various ways, but I'm not at all sure that there are really enough signs to be able to hope that things are going to change in a dramatic way. 
Freddy Santamaría: Is it possible to deal with this situation by means of purely rational arguments of ethics, both formal and modern? Or, in other words, are religious arguments not necessary in ethics?

Peter Singer: I certainly don't think religious arguments are necessary in ethics. I am not a religious person and yet I hold an ethic and so many many other people, in fact, you're in Australia now, which is really a rather secular country, and compared to the United States, religion plays a much less important role in people's lives here, and yet people are I think as you know, are more ethical than people in the United States.

So, I think clearly we don't need religion and any of the writers that I referred to before are notreally religious writers, whether we side with Plato or David Hume or Bentham, Mill and Sidgwick, none of them are really religious writers, so obviously we can develop ethical positions without religion. Is there a point of contact between ethics and religion? Well, yes, because religions do put forward ethics and sometimes they come to the same conclusions as non-religious ethics, so on the question for example of the importance of helping people in extreme poverty, my views and the views of Christians are quite close. On the other hand, on some other questions, my views and the views of Christians tend to be much further apart. So, there are points of contact and we ought to be discussing things with people whose ethics comes from a religious background and we ought to try to see what is actually required in the religion and what isn't and try to encourage people with a religious background to adopt ethical views that lead to greater happiness in this world. But sometimes they believe in an afterlife, which I don't, and then they may not be so focused on this world but may be focused on another world, which I think is a mistake.

Freddy Santamaría: Your book, Animal liberation, attracted the attention of the philosophical community during the 70s, due to the originality of its proposal, because it focused on topics of which little was discussed back at the time among the academic community, what are the main aspects of your book that are currently relevant?

Peter Singer: I think the book is still completely relevant. I think all of the book is completely relevant. It's true that the issues are more discussed today but still it's only a minority of the population who take the arguments of the book seriously. It's been encouraging to see a big upsurge recently in the number of vegetarians and vegans, and that's good; and the animal movement has certainly gained strength and become stronger since the 1970s. But, We still have literally tens of billions of animals in factory farms and in fact the number of animals in factory farms has increased since the 1970 s, because largely the increased prosperity of a number of countries especially in Asia has meant that more meat is eaten. So it's very, very relevant to criticize this and to try to spread the criticism to countries like China where my book has been translated, I would like it to be more widely read of course.

And if the other aspects I discussed, like the experiments on animals are somewhat better controlled today than they were then but still, not really not really sufficiently concerned about the interests of animals. So, the ethical arguments I think also still need to be made. So, I think, you know, I'm planning on updating and revising the book in the next couple of years but I think most of it is still very relevant today.

Freddy Santamaría: Your views on euthanasia, abortion, and your criticism of the sanctity of human life have put you under the criticism of many traditional, conservative, and radical postures. What do you think about traditional and radical postures in philosophy? Do those postures have a religious rather than a rational component?

Peter Singer: Well, some of the criticism of my views on euthanasia and abortion and the sanctity of life have a religious basis and think probably most of them do. So, I mean I think I think that they start from false premises clearly, you know, if they start from the premise that only humans were made in the image of God, I just think that that's not true. They start from the premise that only humans have an immortal soul and animals don't, I don't think that that's true either. So, to some extent it's necessary to point this out that these are questionable premises that the argument start from. But I've also tried to argue that the positions religions take on many of these issues are contradictory or not really sending out a coherent stance. So, for example on the sanctity of life ethic, officially the Roman Catholic Church says, the Popes have said that all human life is of equal value and yet in fact when it comes to decisions about turning off life support on people whose brains are severely damaged, the Church finds sort of ways around this in ways that are really incompatible with the idea of all human life being of equal value. It appeals to doctrines like the doctrine of double effect or the idea that we have an obligation to provide ordinary means of life support but not extraordinary means. But it doesn't even apply these doctrines in a very coherent or consistent manner. So, I try to use internal arguments of inconsistency as well as attacking the more fundamental premises.

Freddy Santamaría: And in the face of his criticism of the sacred life?

Peter Singer: So as I say on these topics euthanasia, abortion and the sanctity of life, because I defend euthanasia and abortion and critique the idea that human life has this universal sanctity or special value that no matter what its quality is. So that's mainly been criticism by criticized by religious groups. On the specific question of euthanasia for infants born with severe disabilities. There has been a 
critique from the militant disability movement. Which asserts that my views undervalue the life of people with disabilities, I guess. And again, I think that in fact that the judgments that I make. That it's better not to be disabled than to be disabled are judgments that pretty much everybody really accepts. So, for example, I defend Parental choice of euthanasia for infants born with severe disability and that's a radical position, but the idea that pregnant women ought to be able to have prenatal diagnosis and terminate the pregnancy if they learn that the fetus has a serious disability is, at least in Australia, universally accepted or, not almost universally accepted, I don't know, if you did an opinion poll I guess it would be around 90 per cent and certainly suddenly and in many different countries over 80 per cent of women told that their fetus let's say we'll have Down syndrome will terminate the pregnancy.

So, this is not really a radical view that I'm holding and in terms of the critique from the disability movement it's exactly the same judgment that says well parents should have choices as to whether they wish to have a child with Down syndrome but sometimes there's not discovered during pregnancy and is discovered. Later on, so I don't accept the radical critique. I don't accept the claim that we should not try to influence whether our children will have disabilities or not. I think most people would agree that it's reasonable to try to avoid having a child with a disability and we do that in many different ways not only through prenatal diagnosis but also by prohibiting the sale of a drug like thalidomide which leads to children with disabilities, or immunizing our daughters against rubella which leaves the children with disabilities. If you really thought that we should not you know we should regard the life of someone with a disability as equally to be welcomed as bringing into the world somebody without a disability, why would we do those things. So, I think it's that is a genuinely radical posture to say that we should be just as welcoming about life the lives of people with disabilities as applies to people without disabilities. This has nothing to do I should emphasize with how we should treat somebody with a disability when they are living in the world and when they're capable of saying that they you know they want to live. Right? I support voluntary euthanasia if anybody's condition is so bad that they think their quality of life is not worth living and they are a rational person, you know, they're not temporally deluded or anything. I think they should be able to end their life and that applies to terminal illnesses as it applies to serious disabilities but if people want to go on living then the community ought to support them and or to help them to be integrated fully into the community and to make life as good as possible for people with disabilities. My view is one about in a sense life before it gets to the point where we can actually ask the person: What do you want to go on living on or not. What do you think of your life?
Freddy Santamaría: By giving rights to animals, don't we discard the idea of the "dignity of human beings"? What is at the core of the theory of rights: theory, theology, reason or power?

Peter Singer: So firstly, I need to make it clear that my view is not based on rights, it's based on essentially on utility on reducing suffering and increasing happiness. So, of course within that framework we might pass laws that give rights to various beings and as a society we might think that it's desirable to recognize that people have a whole set of rights, but the justification for those rights I think should be a utilitarian one, it should be that life will be better for everybody including animals. If we attribute to them certain rights, I don't think the argument comes from a foundation of rights.

And I think if you try to find your theory on rights, you immediately get into great difficulties about saying, well, what rights do people have? what rights do animals have? What rights to people with disabilities and cognitive disabilities have? Some people some of these beings have rights and others not. All of those become very difficult questions and we usually end up just exchanging intuitions about you know what I think the fetus has a right; I think the pregnant woman has a right; How do we solve that? I don't think my view, isn't really based on rights for animals. So, in a sense the premise of that question is mistaken unless it's referring to giving legal rights to animals and I don't think that discards the idea of the dignity of human beings in any important sense or any defensible sense. But I also don't think we should assume that every member of the species Homo sapien has a kind of dignity that no chimpanzee or elephant or whale or horse or pig or dog has. So, this is somewhat parallel to my critique of the sanctity of human life. Just I don't think that just because of being as a member of the species Homo sapiens, irrespective of the condition of their life, their life is sacrosanct in a way that the lives of non-human animals is not. So, I also don't think that all human beings have some kind of dignity that no non-human beings have.

Freddy Santamaría: What is effective altruism? He may be the answer to a good life?

Peter Singer: I think the most fulfilling and meaningful purpose that a human can find is to contributing to making the world better and to refer to the title of one of my books on Effective Altruism to do the most good that we can and I think that that's a fulfilling life in which you do that, but you also enjoy and find satisfaction in doing that and always of course there is some balance between your own interests and well-being and those of your family, we can't completely dismiss that and those strangers but we find some kind of balance where we're doing both of these things and we're content with that kind of life. And so to me a good life is not only a good life for myself personally but a life in which I am 


\section{Annals of Bioethics \& Clinical Applications}

contributing to helping others to have a good life, to reducing suffering of others whether humans or non-human animals. And because we humans are purpose of beings, I think we've evolved as beings who have purposes and then we solve a lot of the problems that ancestors had like, how do we get enough to eat. So, we have to think about other purposes. 